\section{O CONTEXTO DA DOCÊNCIA E SUA INFLUÊNCIA NO SOFRIMENTO PSÍQUICO DE PROFESSORAS DO ENSINO FUNDAMENTAL}

\author{
The context of teaching and its influence on psychic suffering \\ of primary education teachers
}

\section{El contexto de la docencia y su influencia para el sufrimiento psíquico de maestras de la enseñanza fundamental}

\section{RESUMO}

Objetivo: Identificar as causas do sofrimento psíquico referidas por professoras do ensino fundamental. Métodos: Estudo qualitativo, realizado entre dezembro de 2013 e junho de 2014, em Fortaleza, Ceará, Brasil, com dados obtidos por meio de três grupos focais, nos quais se dividiram 26 professoras de 19 escolas. Para a categorização e a interpretação dos dados utilizou-se respectivamente a Análise de Conteúdo na modalidade temática e o Interacionismo Simbólico. Resultados: As participantes identificaram as causas para o sofrimento psíquico no contexto da docência reunidas em três temáticas: fatores ambientais; fatores institucionais; e relações sociais e interpessoais. Os problemas apontados pelas docentes interferem direta ou indiretamente sobre sua saúde mental, causando estresse, angústia, depressão ou desmotivação com o exercício profissional. Conclusão: As temáticas apontadas pelas participantes revelaram que a sobrecarga de trabalho, o ambiente inadequado, a agressividade das crianças, o individualismo de colegas, a falta de estrutura da escola e as pressões institucionais são causas do sofrimento psíquico.

Descritores: Docentes; Estresse Psicológico; Promoção da Saúde.

\section{ABSTRACT}

Objective: To identify the causes of psychic suffering reported by primary school teachers. Methods: Qualitative study conducted between December 2013 and June 2014 in Fortaleza, Ceará, Brazil, with data obtained from three focus groups that included 26 teachers from 19 schools. The categorization and interpretation of data were performed using the content analysis technique based on the thematic modality, and the Symbolic Interactionism. Results: The participants identified the causes for psychic suffering in the context of teaching, which were gathered in three themes: environmental factors; institutional factors and social and interpersonal relationships. The problems identified by teachers interfere directly or indirectly with their mental health, causing stress, anxiety, depression or discouragement about the professional practice. Conclusion: The themes pointed out by the participants revealed that work overload, inadequate environment, aggressiveness of children, individualism of colleagues, lack of school structure and institutional pressures are the causes of psychic suffering.

Descriptors: Faculty; Psychological Stress; Health Promotion.
Artigo Original
1) Universidade de Fortaleza - UNIFOR Fortaleza (CE) - Brasil
Recebido em: 27/05/2016 Revisado em: 30/05/2016 Aceito em: 26/06/2016 


\section{RESUMEN}

Objetivo: Identificar las causas del sufrimiento psíquico referidas por maestras de la enseñanza fundamental. Métodos: Estudio cualitativo realizado entre diciembre de 2013 y junio de 2014 en Fortaleza, Ceará, Brasil, con datos obtenidos a través de tres grupos focales en los cuales se dividieron 26 maestras y 19 escuelas. Para la categorización y la interpretación de los datos se utilizó respectivamente el Análisis de Contenido en la modalidad temática y el Interaccionismo Simbólico. Resultados: Las participantes identificaron las causas para el sufrimiento psiquico en el contexto de la docencia reunidas en tres temáticas: factores ambientales; factores institucionales; y relaciones sociales e interpersonales. Los problemas relatados por las maestras influyen directa o indirectamente en su salud mental llevando al estrés, la angustia, la depresión o no motivación para el ejercicio de la profesión. Conclusión: Las temáticas relatadas por las participantes revelaron que la sobrecarga de trabajo, el ambiente inadecuado, la agresividad de los niños, el individualismo de los compañeros, la falta de estructura de la escuela y las presiones de la institución son causas del sufrimiento psíquico.

Descriptores: Docentes; Estrés Psicológico; Promoción de la Salud.

\section{INTRODUÇÃO}

O trabalho é entendido como uma das funções psicológicas do sujeito, na medida em que desempenha um papel de mediação simbólica entre o trabalho em si, realizado pelo sujeito, as ações realizadas com os outros e os objetos da atividade laboral, podendo impactar direta ou indiretamente tanto nos processos de saúde como de doença, uma vez que promove sofrimento e/ou autorrealização ${ }^{(1)}$.

O sofrimento psíquico no trabalho pode ser compreendido como a perda de significado da atividade laboral, o que traz prejuízos à vitalidade dos sujeitos, tornando psicologicamente nefasta a realização do trabalho(2).

Por sua vez, saúde mental no trabalho constitui a possibilidade de enfrentar os desafios da vida de modo criativo, construindo um sentido e um significado sobre as atividades impostas e os resultados a serem alcançados ${ }^{(1)}$. É a oportunidade de pensar e falar com autonomia sobre a qualidade do trabalho, implicando-se nas mudanças necessárias para a realização de um "trabalho bem-feito"(2).

Nas últimas décadas, a relação entre saúde mental e trabalho tem recebido atenção crescente devido às várias mudanças ocorridas no ambiente ocupacional. Entre essas mudanças, estão a intensificação das atividades trabalho, a alta produtividade, o avanço tecnológico e a precarização das relações que têm resultado em ampliação significativa no número de trabalhadores com problemas de saúde, estresse e burnout $t^{(3,4)}$.

A Organização Mundial da Saúde (OMS) estima índices de $30 \%$ de transtornos mentais na população trabalhadora ocupada até 2020, com prevalência para o aumento dos casos de depressão, tornando-se a segunda maior causa de afastamento por incapacidade e perdendo apenas para as doenças isquêmicas do coração ${ }^{(5)}$.

A escola não escapa incólume às mudanças apontadas ${ }^{(6)}$, pois pesquisas afirmam que as condições de trabalho dos docentes brasileiros são consideradas precárias e têm sido apontadas como geradoras de adoecimento físico e psicológico $^{(7)}$. Dentre os impactos mais evidentes, está o fato de que a escola precisou assumir a função de preparar para o mercado mão de obra qualificada e multiespecializada, numa estrutura de sala de aula voltada para a racionalização e a especificidade do conhecimento ${ }^{(6)}$. Desse modo, a educação passou a ganhar moldes de mercadoria, tornando-se totalmente imersa nos novos padrões de eficácia e produtividade, uma vez que a sua qualidade, na atualidade, é medida pelos índices de avaliações e pelos números de educandos aprovados em provas de vestibulares e concursos ${ }^{(6)}$.

Os professores evidenciam um forte sentimento de frustração ao se depararem com o referido cenário da educação e a constante desvalorização social da profissão ${ }^{(8)}$. Acrescente-se a isso os sentimentos de angústia, desgosto, raiva, desesperança, desmotivação, cansaço e estresse apontados pelos professores diante das pressões existentes na organização do trabalho ${ }^{(9,10)}$. Tais sentimentos produzem sofrimento psíquico associado à atividade docente e podem ocasionar transtornos mentais comuns, duradouros ou transitórios, com o consequente afastamento do docente das atividades laborais ${ }^{(9-11)}$. $\mathrm{Na}$ realidade brasileira, os distúrbios psíquicos são uma das principais causas de afastamento do trabalho docente ${ }^{(12)}$. Não é sem razão que dentre os trabalhadores mais investigados nas publicações sobre os transtornos mentais relacionados ao trabalho estão os professores ${ }^{(13)}$.

Apesar do impacto da saúde do trabalhador na cadeia produtiva e dos debates incitados pelo tema na Saúde Coletiva, pouca atenção tem sido dada às políticas de saúde voltadas ao trabalhador e aos programas de intervenção ${ }^{(14)}$.

Um exemplo desse paradoxo é o Programa Saúde na Escola $(\mathrm{PSE})^{(15)}$, que foi instituído pelo Decreto $\mathrm{n}^{\mathrm{o}} 6.286$, de 5 de dezembro de 2007, com o objetivo de contribuir para a formação integral dos estudantes por meio de ações de promoção, prevenção e atenção à saúde, com vistas ao enfrentamento das vulnerabilidades que comprometem o pleno desenvolvimento de crianças e jovens da rede pública de ensino no Brasil. Apesar de definir como público beneficiário os estudantes da educação básica, gestores 
e profissionais de educação e saúde, comunidade escolar e, de modo mais ampliado, estudantes da Rede Federal de Educação Profissional e Tecnológica e da Educação de Jovens e Adultos (EJA), os aspectos que incluem a saúde integral do professor não são cobertos pelo $\mathrm{PSE}^{(15)}$. Esse assunto merece reflexão em virtude do importante papel que o professor desempenha no ambiente educacional, dos riscos e agravos aos quais está exposto, o que também inclui consequências à sua saúde física e mental ${ }^{(9,11)}$.

O PSE afirma que a escola é um espaço privilegiado para a convivência social e o estabelecimento de relações favoráveis à promoção da saúde pelo caminho de uma educação integral ${ }^{(15)}$. É difícil, porém, haver educação integral se a saúde do professor está comprometida ${ }^{(9,11)}$. Um exemplo dessa situação é o adoecimento dos docentes, que compromete a qualidade do ensino, pois o absenteísmo e as licenças de saúde desses profissionais ainda constituem uma realidade nas escolas brasileiras ${ }^{(12)}$.

No Brasil, segundo o Censo Escolar ${ }^{(16)}$, há aproximadamente dois milhões de docentes na educação básica. Esses profissionais são responsáveis por lecionar para mais de 52 milhões de alunos. Parte dos professores exerce suas atividades em mais de uma etapa do ensino, concentrando-se mais de um milhão e meio no ensino fundamental.

A realidade expressada no cenário brasileiro não diverge dos números contabilizados na Educação Básica da rede municipal de ensino do Município de Fortaleza, que dispõe de 9.191 docentes. Desse total, mais de $80 \%$ concentram-se no ensino fundamental. A faixa etária predominante é de 40 a $49 \operatorname{anos}^{(17)}$.

Considerando, ainda, que os sintomas relacionados ao estresse são mais frequentes em mulheres ${ }^{(18)}$, direcionou-se a presente pesquisa para o cuidado com o sofrimento psíquico das professoras, o que também influencia diretamente o bem-estar e a qualidade de vida desse público.

Nesse contexto, entende-se a estreita relação entre o cuidado com a saúde mental das professoras e a promoção da saúde, pois esta remete ao conjunto de estratégias que possibilita potencializar a autonomia, a emancipação e a adoção de intervenções que possam melhorar as condições de trabalho, a saúde e a qualidade de vida dessa categoria profissional $^{(19)}$.

Com base no exposto e na relevância que a preservação da saúde mental tem para o exercício da docência, este trabalho objetivou identificar as causas do sofrimento psíquico referidas por professoras do ensino fundamental.

\section{MÉTODOS}

Trata-se de um estudo qualitativo, exploratório, realizado de dezembro de 2013 a junho de 2014, por meio de três grupos focais. Utilizou-se a metodologia qualitativa por ser esta capaz de incorporar o significado e a intencionalidade como inerentes aos atos, às relações $\mathrm{e}$ às estruturas sociais ${ }^{(20)}$. Nesse contexto, considera-se a importância do conhecimento, o qual constitui o processo pelo qual as pessoas intuem, apreendem e expressam suas percepções, sem desprezarem a subjetividade. Nessa perspectiva, entende-se que as pessoas apreendem o mundo, exteriorizam-no e, assim, produzem conhecimento.

A amostra foi constituída de 26 professoras, com idades entre 24 e 66 anos, extraídas de um grupo de 361 professoras do ensino fundamental, de 60 escolas públicas do município de Fortaleza, Ceará, Brasil, que responderam a um questionário sobre as características socioeconômicas, formação e vida profissional, condições de saúde, principalmente a vocal. Ressalta-se que participaram dos grupos focais representantes de escolas situadas nos seis Distritos de Educação de Fortaleza.

Os critérios de inclusão considerados foram: ser professora do ensino fundamental I e/ou II, estar em plena atividade em sala de aula, não estar em licença médica devido a problemas vocais e/ou não ter indicação para tal e ter disponibilidade para participação no grupo focal. Assim, realizaram-se três grupos focais, cada um com duração média de 2 horas e 30 minutos. Do primeiro grupo focal participaram 12 professoras; do segundo, sete; e do terceiro, outras sete.

Para esse fim, utilizou-se um roteiro com questões norteadoras sobre a temática em pauta, o qual foi elaborado com base no Interacionismo Simbólico ${ }^{(21)}$. Aplicaramse as seguintes questões norteadoras: "No contexto da sua atividade como professora, quais são os fatores que interferem na sua saúde mental?"; "Isso afeta a sua qualidade de vida e o seu exercício profissional? Como?".

Utilizou-se a saturação dos dados como critério para a definição final da amostra e da coleta dos dados, uma vez que esta é atingida, em pesquisa qualitativa, quando o pesquisador já tiver coletado certa diversidade de ideias e, com a continuidade das entrevistas ou de observação adicional, não mais identificar novos achados ${ }^{(22)}$.

Após leitura detalhada das transcrições dos grupos focais, realizou-se a análise dos dados, utilizando-se a Análise de Conteúdo na modalidade temática ${ }^{(23)}$. Dessa forma, identificaram-se três temáticas: fatores ambientais; fatores institucionais; e relações sociais e interpessoais. Essas temáticas refletem os problemas apontados pelas docentes que interferem direta ou indiretamente sobre seu sofrimento psíquico, causando estresse, angústia, depressão ou desmotivação com o exercício profissional.

A interpretação dos dados fundamentou-se no Interacionismo Simbólico ${ }^{(21)}$, pois este possibilitou 
compreender as associações entre o conhecimento, a ação e a interpretação dos aspectos da docência e suas interferências sobre a saúde mental das professoras. A literatura $^{(3,4,8,10,11,24)}$ que trata de questões voltadas à saúde mental dos professores também respaldou a apresentação e discussão dos achados. Nessa fase, extrapolou-se o âmbito dos resultados empíricos e examinou-se minunciosamente o referencial teórico, na tentativa de captar a percepção das professoras sobre os fatores relacionados ao tema central deste estudo.

As professoras foram nominadas pela letra "P", que remete à palavra "professora", seguida dos números 1 a 26, cuja estratégia possibilitou resguardar o anonimato das participantes.

A presente pesquisa constitui o recorte de uma tese de doutorado e está de acordo com a Resolução do CNS $\mathrm{n}^{\circ} 466 / 12$, tendo sido aprovada pelo Comitê de Ética em Pesquisa com Seres Humanos da Universidade de Fortaleza sob parecer $n^{\circ} 899.798$.

\section{RESULTADOS E DISCUSSÃO}

A presente pesquisa possibilitou verificar que o contexto da docência exerce influência no sofrimento psíquico das professoras do ensino fundamental investigadas, uma vez que, sob a ótica das participantes, sua saúde mental é impactada direta ou indiretamente pelos fatores ambientais, aspectos institucionais e, ainda, pelas relações sociais e interpessoais.

A exposição intensiva a fatores que desencadeiam desconforto, cansaço e estresse causa sofrimento psíquico para as docentes, uma vez que estas precisam aplicar estratégias para preservar sua saúde, modificando metodologias de ensino e fazendo com que os alunos participem mais ativamente das aulas ${ }^{(25)}$. As mudanças físicas causadas pelas reações de estresse, ansiedade e nervosismo, associadas a situações de violência e fatores ambientais, também levam ao mal-estar físico e mental ${ }^{(18,26)}$.

A literatura ${ }^{(24)}$ revela, ainda, que o sistema de trabalho, ao ter estabelecido metas produtivas para os professores, similares aos perfis do processo de produção industrial que se relacionam à ascensão profissional e a resultados como método de reconhecimento e remuneração, promoveu uma massificação das políticas e práticas de ensino. Esse fato trouxe prejuízos à qualidade de vida e à saúde ocupacional dos professores ${ }^{(9,11)}$.

Com base no exposto e diante da análise dos relatos das participantes, para aprofundar os achados da investigação e possibilitar uma reflexão mais detalhada sobre o assunto em pauta, serão discutidas as temáticas identificadas a partir dos grupos focais, com suas respectivas ideias associadas.

\section{Fatores ambientais}

As condições ambientais de trabalho remetem a fatores internos e externos à escola, os quais exercem influências diretas ou indiretas na saúde mental das professoras, uma vez que estas os referenciam nitidamente em seus relatos.

"[...] A estrutura da escola, a estrutura da sala de aula... Aquilo é um terror para a gente! Se for levantar os fatores são inúmeros. As salas, a poeira, os ventiladores barulhentos e empoeirados, o barulho dos meninos, você competindo com as crianças querendo ser ouvidas, você tentando se fazer ouvir... As condições de trabalho são difíceis, porque a escola está cercada de mazelas sociais... todas as mazelas estão dentro da escola...essa questão da droga, da violência, tudo isso... a gente recebe toda essa carga e, mesmo assim, não vem nenhum suporte para que a gente trabalhe com isso." (P17)

Pesquisas revelam que a saúde do professor é objeto de interferências de diversos fatores negativos, que vão desde a precariedade das condições de trabalho (sejam elas ambientais, materiais ou relacionais) até as dificuldades relativas à atenção e ao acesso à saúde ${ }^{(12,27,28)}$. Nesse sentido, ressalta-se a importância de cuidar do ambiente de trabalho para que a promoção da saúde do professor seja alcançada de forma efetiva e integral ${ }^{(19,29)}$.

"Já imaginou numa sala com quarenta e quatro alunos... nós lá na escola temos salas com trinta e cinco, trinta e sete alunos e, quando a gente começa a falar, um começa a fazer um barulho, um conversa, um cochicha... Isso traz uma angústia muito grande e faz com que a gente se sinta impotente..." (P20)

Estudos apontam que o número excessivo de alunos aumenta o ruído ambiental, a violência na escola, além de ensejar um maior esforço do professor durante as aulas e na mediação de $\operatorname{conflitos}^{(30,31)}$. Ademais, outros estudos mostram que o excesso de atividades, as demandas do ambiente de trabalho e a pressão das instâncias superiores constituem fatores desencadeantes de estresse e ansiedade nos professores ${ }^{(26,32)}$.

Condições hiperdimensionadas de suportação física e emocional do professor são elementos inerentes à situação de exploração no mundo do trabalho. Estudos comprovam que o adoecimento ocupacional, em muitos aspectos, diz respeito às condições ambientais. Porém, isso é considerado de menor valor, pois o que se vê são soluções para o trabalhador se readaptar ou redimensionar essas condições para manter o status quo do sistema de trabalho ${ }^{(24)}$.

A intensa jornada de trabalho e a exigência de realização simultânea de várias atividades pelas professoras, incluindo os trabalhos que levam para fazer em casa, trazem sofrimento, desmotivação, cansaço e estresse. O acúmulo de responsabilidades acarreta riscos à saúde geral dessas profissionais $^{(33)}$. 
Dentre as ideias associadas às interferências do ambiente na saúde mental das professoras, observa-se a presença de fatores internos (ruído ambiental, falta de higiene, temperatura, falta de infraestrutura e número excessivo de alunos) e externos (droga, violência e mazelas sociais). Essa realidade contraria a premissa de que a escola seja um espaço social, onde seja desenvolvida a tomada de consciência coletiva, com base na integralidade, para melhores condições de trabalho, e se torne um ambiente saudável e promotor da saúde. Para que isso aconteça, é necessária uma tomada de consciência dos gestores, a fim de que implementem políticas públicas capazes de minimizar os riscos decorrentes dessas condições adversas ${ }^{(34)}$.

\section{Fatores institucionais}

Dentre os fatores institucionais que prejudicam a saúde mental, as professoras investigadas na presente pesquisa referiram a falta de preocupação do empregador em relação à sua saúde geral e, mais especificamente, à sua saúde mental. Apontaram as dificuldades enfrentadas por elas para serem vistas como pessoas que precisam de cuidado. O afastamento de sala de aula é outro aspecto referido pelas participantes como algo que traz sofrimento. Com isso, o "cuidar-se" é tomado como "deixar de cuidar":

"Agora, eu faço uma pergunta assim: se eu vou para um tratamento, eu saio da minha sala de aula eu já vou angustiada, porque já deixei um problema... Esse tratamento vai servir? Porque no momento que atinge o meu emocional... Vai servir esse tratamento?" (P1)

O discurso da professora é reflexo da árdua jornada à qual os docentes em geral são submetidos. Professores e professoras, além de manterem dupla jornada de trabalho, número elevado de horas trabalhadas e vínculo com mais de uma instituição de ensino, também sofrem cobranças psicológicas, com exigências e cumprimento de ordens que levam à exaustão profissional e à falta de cuidado com sua saúde ${ }^{(4)}$.

Nesse sentido, observa-se em outro relato a angústia de uma professora na tentativa de buscar um tratamento de saúde. Segundo ela, a pressão institucional foi tão elevada que acabou se envolvendo em situações conflituosas para tentar uma alternativa ao seu problema:

"Foi no início do ano passado e foi um trauma pra mim... com relação à liberação da escola para fazer o tratamento, pois não deixaram [os gestores] eu sair. Gente, foi complicado e me disseram: 'Procure dia de sábado'... Você ser liberada para se cuidar? Você pode estar morrendo e tem que permanecer dentro da sala de aula, dar a aula sem voz e ficar lá mesmo... Foi o que eu senti durante o tratamento, foi um descaso com a minha saúde e também com os alunos. Se vocês tivessem passado pela mesma experiência... Porque para mim foi traumática... Tive que brigar com a direção, a vicecoordenação [...]" (P15)

$\mathrm{O}$ adoecimento pode ser demarcado pela vergonha do trabalhador, pela sua culpabilização e pela individualização do adoecimento, de modo a separar as condições e a organização do trabalho da produção da doença. A situação de afastamento do trabalho impõe uma revisão dos modos de vida desses trabalhadores, desestabiliza, tensiona e exige recursos para a busca ou a produção de formas de fuga $^{(35)}$. O afastamento pelo adoecimento é vivenciado como rompimento com o trabalho e, muitas vezes, aparece através do corpo. O corpo do trabalho invade o corpo do trabalhador até o ponto de insustentabilidade da situação. E, no momento do adoecimento, o corpo do trabalhador diluise no corpo do trabalho e eles não mais se diferenciam - o corpo do trabalhador é só trabalho, até o adoecimento e a incapacidade ${ }^{(35)}$.

No caso do adoecimento pelo trabalho, o corpo pode deixar de ser corpo múltiplo e diversificado do trabalhador, pois é dor e sofrimento, e o trabalho deixa de ser trabalho com potencialidade de criação e de produção, pois é restrição, impotência e limitação ${ }^{(35)}$. No processo de saúde e doença, as práticas devem responder às necessidades ou demandas por saúde mais ampliada, buscando as raízes dos problemas através das políticas públicas ${ }^{(36)}$.

$\mathrm{O}$ adoecimento e o afastamento de professores culminam no comprometimento de outros em decorrência do chamado "presenteísmo". Esse fenômeno ocorre quando a ausência de professores sobrecarrega outros professores, já com a saúde abalada. Esse fato desencadeia queixas e sintomas, como dor de cabeça e nas costas, dificuldades respiratórias, alergias, irritação, pressão alta, alterações gastrintestinais, artrite e depressão $0^{(12)}$.

Além da sobrecarga do professor imposta pela reforma do sistema educacional, as professoras sentem que sua profissão é desvalorizada pela sociedade, pais, alunos e gestores, fazendo com que se considerem desrespeitadas ${ }^{(32)}$.

Outro aspecto relevante é que, entre os profissionais da voz, os professores buscam menos do que o esperado os serviços de otorrinolaringologia ou fonoaudiologia, apesar dos diversos fatores de risco aos quais estão expostos no ambiente e dos sintomas que referem ${ }^{(37,38)}$. Dentre as várias causas atribuídas a essa situação, uma delas pode ser a angústia de ter que enfrentar uma série de situações no ambiente profissional que prejudiquem essa procura, além do senso de responsabilidade com o exercício profissional e o desejo de não deixarem seus alunos sem aula ${ }^{(28)}$.

Essa realidade precisa ser discutida e revisada para que as condições institucionais não prejudiquem a saúde mental dos professores ${ }^{(24,35)}$. 


\section{Relações sociais e interpessoais}

As questões relacionadas ao estresse causado pelo ambiente de trabalho também chamam atenção, pois, além do ambiente físico, as relações interpessoais são fatores que predispõem às alterações na saúde vocal e mental ${ }^{(24,35)}$.

Dificuldades no relacionamento interpessoal, na interação social, principalmente com os pares da atividade profissional, no lidar com as emoções e a necessidade de expor o que acontece subjetivamente foram alguns aspectos descritos pelas professoras investigadas no atual estudo, como algo que, muitas vezes, as leva a um adoecimento psíquico.

"[...] A gente é maltratada dentro da sala de aula, a gente é maltratada pelos nossos colegas na sala dos professores e a gente é maltratada, principalmente, pelo sistema educacional falido... Junta isso com o problema da estrutura da escola, junta a pressão da direção, junta o desestímulo, a desmotivação da maioria dos nossos colegas... Cada um fazendo só a sua parte e cada um que se dane se você se sente frustrada... Então, essa agressão que a gente sofre... É muito pesada psicologicamente, por isso, há dois anos, eu tive que fazer tratamento." (P8)

Entre os professores da rede municipal de São Paulo, $60 \%$ dos educadores referem presença de alterações na saúde e apontam fatores ambientais, organização de trabalho e relacionais como contribuintes para a ocorrência desses problemas $^{(39)}$.

"[... ]Antes, eu chorava, ficava na sala de aula e sabia que logo ia passar... Eu inventava logo uma coisa diferente e tirava um tempo de mim mesma, dava a volta por cima... Agora, eu não consigo mais controlar essa emoção. Eu saio, peço ajuda a alguém da escola para ficar um pouco na minha sala, eu vou ao banheiro, lavo o rosto e retomo... Me recomponho para poder voltar à sala de aula..." (P1)

A fala da professora remonta ao fato de que os grupos humanos existem em ação e devem ser vistos num continuum de interação que pode ser modificado pelo contexto e pelas necessidades. As interações sociais ensejam ações e reações, as quais podem mudar as interpretações das situações e objetos da vida diária ${ }^{(21)}$. A escola é um espaço de convivência social, porém, é estudada amplamente pelas condições adversas à saúde mental do professor ${ }^{(29-31,40)}$.

O mal-estar causado pelas relações conflituosas em sala de aula, com outros professores ou gestores ou, ainda, com os pais dos alunos fazem com que as professoras busquem alternativas para enfrentar o problema. Uma dessas estratégias consiste na troca de experiências e no desabafo com as colegas, como mostra o relato a seguir:
"[...] Na hora do intervalo, eu procuro não falar nada, apesar de observar as minhas colegas que, na hora do intervalo, fazem um momento de muito desabafo do que aconteceu na sala de aula... Muitas já utilizam esse tempo pra desabafar e ai a gente se depara muito com a emoção e realmente nessa hora é que eu fico observando e penso: 'Nossa! Como a gente é emotiva e coloca tudo isso na voz e na emoção!'” (P16)

Esse relato denota a necessidade que essas profissionais sentem de serem ouvidas, porém, não dispõem de tempo ou serviços especializados para que possam participar de grupos de reflexão, o que poderia auxiliá-las a lidar com esse cenário comprometedor da saúde mental e qualidade de vida ${ }^{(41)}$.

Uma pesquisa sobre grupos de reflexão realizada com professores do ensino fundamental mostrou a importância desse tipo de estratégia voltada a esse público, posto que eles a compreenderam como um momento importante de apoio e troca de experiências. Nesse espaço, foi possível que esses profissionais expusessem suas insatisfações, conflitos, descrenças, angústias e ansiedades ante as situações vivenciadas na vida profissional ${ }^{(41)}$. Esses professores externaram muitos problemas de relacionamento e de aceitação. Outra constatação dos autores recaiu sobre a percepção das condições das escolas, que dificultam a realização de trabalhos de grupo e a relação interpessoal ${ }^{(41,42)}$.

No presente estudo, verificou-se que as professoras reconhecem a falta de atenção psicológica no contexto escolar, e que esses desabafos e trocas de experiências acontecem na rotina diária, durante os intervalos de aula, na sala dos professores, entre as professoras com afinidade entre si ou com gestores que inspiram acolhimento e confiança. Para as participantes da atual pesquisa, essa estratégia funciona como "válvula de escape", como forma de reduzir a tensão emocional e aprender com as profissionais mais experientes, na tentativa de lidar com a indisciplina dos alunos, com a desvalorização da profissão, com as agressões que sofrem de pais, alunos e gestores, além das condições ambientais adversas.

Nesse contexto, é importante que se conheça a forma de uma pessoa ou grupo social enxergar as diversas situações sociais, suas barreiras e possibilidades, para que se compreenda os seus comportamentos. A interpretação possibilita esse domínio e a compreensão de que as ações das pessoas implicam reações, as quais também estão impregnadas pelas questões culturais ${ }^{(43)}$.

Alguns docentes não estabelecem relações interpessoais de forma satisfatória, devido à disputa profissional no próprio local de trabalho, à comunicação com os outros profissionais da escola e à falta de integração no ambiente do trabalho. Em decorrência disso, denotam-se experiências de 
sofrimento, com presença do sentimento de competitividade e ausência de solidariedade ${ }^{(44,45)}$.

Apesar de os professores conseguirem identificar os diversos aspectos que causam sofrimento psíquico, os dados apontam para a escassez de informações sobre essa temática, o que sinaliza para a necessidade de implementação de estratégias que promovam a saúde mental na escola. Destaca-se que $80,6 \%$ dos participantes consideraram muito importante a aquisição de conhecimentos sobre saúde mental e o acesso a materiais educativos sobre o assunto ${ }^{(46)}$.

Assim, a promoção da saúde do professores é fator essencial para o avanço das estratégias de empoderamento dessa população, visando o enfretamento das condições geradoras de sofrimento psíquico, o que perpassa as ações de educação em saúde, a ampliação do acesso à informação, o apoio emocional, os ajustes estruturais e organizacionais, além da melhoria das relações interpessoais ${ }^{(46)}$.

\section{CONSIDERAÇÕES FINAIS}

$\mathrm{O}$ estudo evidenciou que as professoras analisadas identificaram vários aspectos que causam sofrimento psíquico e que estão relacionados ao contexto da docência, apontando questões albergadas nos fatores ambientais, nos fatores institucionais e nas relações sociais e interpessoais. Esse fato leva à reflexão de que o docente precisa ser reconhecido e valorizado, devendo ser visto não apenas como um "instrumento de trabalho", mas como uma pessoa em sua complexidade, para que haja o alcance da saúde integral na escola. Esse profissional deve ser percebido como um sujeito ativo neste processo, desde que seja envolvido e beneficiado por ações voltadas à sua saúde.

Outros fatores que chamam atenção nos resultados dizem respeito às cargas de trabalho excessivas, às condições de trabalho inadequadas e à falta de apoio institucional para o recebimento de cuidado para a saúde do professor. Essas são questões amplas e de cunho social, que interferem diretamente no contexto da escola e na satisfação e motivação desse profissional.

Nesse contexto, a escola deve ter uma visão ampla de todos os seus aspectos e atores, no intuito de compreender o contexto que inclui os docentes e promover um ambiente saudável, favorecendo boas condições de trabalho e aprendizagem.

Além disso, outras ações são necessárias, tais como: reconhecer a importância da estética da escola e o efeito psicológico direto que este aspecto exerce sobre professores e alunos; estar fundamentada num modelo de saúde que inclui a interação dos aspectos físicos, psíquicos, socioculturais e ambientais; promover a participação ativa dos alunos; perceber que o desenvolvimento da autoestima e da autonomia pessoal do professor são fundamentais para a promoção da saúde; valorizar a promoção da saúde na escola para todos os que nela estudam e trabalham; ter uma visão ampla dos serviços de saúde voltados para o escolar/ reforçar o desenvolvimento de estilos saudáveis de vida e oferecer opções viáveis e atraentes para a prática de ações que promovam a saúde.

Entretanto, o descontentamento com o ambiente, a agressividade das crianças, o individualismo de alguns colegas professores, a falta de estrutura da escola e as pressões institucionais, refletidas na falta de apoio dos gestores ao professor, foram elementos identificados como catalisadores dos problemas relacionados à saúde mental da população estudada, pois evocam sentimentos de frustração, angústia, tristeza e desmotivação.

Sugere-se que os dados do presente estudo sejam amplamente discutidos pelos atores envolvidos, a fim de possibilitar o planejamento de ações resolutivas para os problemas em pauta. Isso, consequentemente, poderá favorecer a implementação de ações voltadas à saúde e ao bem-estar de toda a comunidade escolar, incluindo, de forma evidente, o professor.

\section{REFERÊNCIAS}

1. Bendassolli PF, Gondim SMG. Significados, sentidos e função psicológica do trabalho: Discutindo essa tríade conceitual e seus desafios metodológicos. Av Psicol Latinoam.. 2014;32(1):131-47.

2. Clot Y. Trabalho e Poder de Agir. Belo Horizonte: Fabrefactumo; 2010.

3. Zanelli JC. Estresse nas organizações de trabalho: Compreensão e intervenção baseadas em evidências. In: Zanelli JC. Trabalho, saúde e construção de vida. Porto Alegre: Artmed; 2010. p. 19-32.

4. Teixeira LN, Rodrigues AL, Silva FM, Silveira RCP. As possíveis alterações no estilo de vida e saúde de professores. Rev Enferm Cent.-Oeste Min. 2015;5(2):1669-83.

5. Jardim SR, Ramos A, Glina DMR. Diagnóstico e nexo com o trabalho. In: Glina DMR, Rocha LE, organizadores. Saúde mental no trabalho da teoria à prática. São Paulo: Roca; 2010. p. 3-30.

6. Weschenfelder FZ, Trindade GA. Trabalho docente e desenvolvimento capitalista: Uma articulação perversa para a saúde do educador. Synergismus Syentifica. 2011;6(1):1-7.

7. Codo W, coordenador. Educação: carinho e trabalho. Rio de Janeiro: Vozes; 1999. 
8. Arruda RP, Catrib AMF, Brasil CCP, Batista MH, Sampaio PP. The Pain of teaching: considerations regarding educational endeavors. US-China Education Review A. 2015;5(4):267-276.

9. Mendes MLM. A precarização do trabalho docente e seus efeitos na saúde dos professores da rede municipal de ensino do Recife. Humanae. 2015;9(1):91-109.

10. Porto LA, Carvalho FM, Oliveira NF, Silvany AM Neto, Araújo TM, Reis EJFB. Associação entre distúrbios psíquicos e aspectos psicossociais do trabalho de professores. Rev Saúde Pública. 2006;40(5):818-26.

11. Reis EJFB, Araújo TM, Carvalho FM, Barbalho L, Silva MO. Docência e Exaustão Emocional. Educ Soc. 2006;27(94):229-53.

12. Van Houtte E, Claeys S, Wuyts F, Van Lierde K. The impact of voice disorders among teachers: vocal complaints, treatment-seeking behavior, knowledge of vocal care, and voice-related absenteeism. J Voice. 2011;25(5):570-5.

13. Bárbaro AM, Robazzi MLDCC, Pedrão LJ, Cyrillo RMZ, Suazo SVV. Transtornos mentais relacionados ao trabalho: revisão de literatura. SMAD, Rev. eletrônica saúde mental alcool drog [Internet]. 2009 [acesso em 2015 Ago 26];5(2):1-16. Disponível em: http://www. revistas.usp.br/smad/article/view/38695

14. Mudim MCB. Saúde mental e trabalho: levantamento das publicações na SCIELO E PEPSIC. Barbarói. 2012;36:110-9.

15. Brasil. Programa Saúde na Escola. Decreto $n^{0}$ 6286, de 05 de dezembro de 2007. Brasília: Presidência da República; 2007.

16. Ministério da Educação (BR). Censo Escolar 2009. Brasília: Ministério da Educação; 2009.

17. Secretaria Municipal de Ensino de Fortaleza (CE). Relatório sobre docentes da rede municipal de ensino 2012. Fortaleza; 2012.

18. Holmqvist S, Santtila P, Lindström E, Sala E, Simberg $\mathrm{S}$. The association between possible stress markers and vocal symptoms. J Voice. 2013;27(6):787.e1-787.e10.

19. Silva CO, Ramminger T. O trabalho como operador de saúde. Ciênc Saúde Coletiva. 2014;19(12):4751-8.

20. Minayo MCS. O desafio do conhecimento: pesquisa qualitativa em saúde. 12ª ed. São Paulo: Hucitec; 2010.

21. Blumer H. Symbolic interacionism: perspective and method. Los Angeles: University of California Press; 1969.
22. Salgado CM. El muestro en investigación cualitativa. Principios básicos y algunas controvérsias. Ciênc Saúde Coletiva. 2012;17(3):613-9.

23. Bardin L. Análise de Conteúdo. Portugal: Edições 70; 2009.

24. Forattini CD, Lucena C. Adoecimento e sofrimento docente na perspectiva da precarização do trabalho. Laplage Revista. 2015;1(2):32-4.

25. Vaz C, Regina M, Severo LO, Borges AM, Bonow CA, Rocha LP et al. Voice disorders in teachers. Implications for occupational health nursing care. Invest Educ Enferm. 2013;31(2):252-60.

26. Costa DB, Lopes LW, Silva EG, Cunha GMS, Almeida LNA, Almeida AF. Fatores de risco e emocionais na voz de professores com e sem queixas vocais. Rev CEFAC. 2013;15(4):1001-10.

27. Araújo TMD, Reis EJFBD, Carvalho FM, Porto LA, Reis IC, Andrade JMD. Fatores associados a alterações vocais em professoras. Cad Saúde Pública. 2008;24(6):1229-38.

28. Luchesi KF, Mourão LF, Kitamura S, Nakamura HY. Problemas vocais no trabalho: prevenção na prática docente sob a óptica do professor. Saúde Soc. 2009;18(4):673-681.

29. Pereira EF, Teixeira CS, Andrade RD, Bleyer FTDS, Lopes ADS. Associação entre o perfil de ambiente e condições de trabalho com a percepção de saúde e qualidade de vida em professores de educação básica. Cad Saúde Colet (Rio J). 2014;22(2):111-9.

30. Guidini RF, Bertoncello F, Zanchetta S, Dragone MLS. Correlações entre ruído ambiental em sala de aula e voz do professor. Rev Soc Bras Fonoaudiol. 2012;17(4):398-404

31. Servilha EAM, Pereira PM. Condições de trabalho, saúde e voz em professores universitários. Rev Ciênc Méd PUCCAMP. 2008;17(1):21-31.

32. Karmann DF, Lancman S. Professor: intensificação do trabalho e o uso da voz. Audiol Commun Res. 2013;18(3):162-70.

33. Souza CLD, Carvalho FM, Araújo TMD, Reis EJFBD, Lima VMC, Porto LA. Fatores associados a patologias de pregas vocais em professores. Rev Saúde Pública. 2011;45(5):914-21.

34. Xavier IALN, Santos ACO, Silva DM. Saúde vocal do professor: intervenção fonoaudiológica na atenção primária à saúde. Rev CEFAC. 2013;15(4):976-85. 
35. Ramos MZL, Tittoni J, Nardi HC. A experiência de afastamento do trabalho por adoecimento vivenciada como processo de ruptura ou continuidade nos modos de viver. Cad Psicol Soc Trab. 2008;11(2):209-21.

36. Amorim AKM, Dimenstein M. Desinstitucionalização em saúde mental e práticas de cuidado no contexto do serviço residencial terapêutico. Ciênc Saúde Coletiva. 2009;14(1):195-204.

37. Medeiros AM, Assunção AA, Barreto SM. Alterações vocais e cuidados de saúde entre professoras. Rev CEFAC. 2012;14(4):1-7.

38. Roy N, Merrill RM, Thibeault S, Gray SD, Smith EM. Voice disorders in teachers and the general population: effects on work performance, attendance, and future career choices. J Speech Lang Hear Res. 2004;47(3):542-51.

39. Ferreira LP, Giannini SP, Figueira S, Silva EE, Karmann DDF, Souza TM. Condições de produção vocal de professores da rede do município de São Paulo. Disturb Comum. 2003;14(2):275-308.

40. Tavares DDF, de Oliveira RAR, Mota RJ Júnior, Oliveira CEP, Marins JCB. Qualidade de vida de professoras do ensino básico da rede pública. Rev Bras Promoç Saúde. 2015;28(2):191-7.

41. Carraro PR, Andrade AS. O professor do ensino fundamental em grupos de reflexão. Rev Mal-Estar Subj. 2011;11(4):1339-78.
42. Mont'Alverne DGB, Catrib AMF. Promoção da saúde e as escolas: como avançar. Rev Bras Promoç Saúde. 2013;26(3):307-8.

43. Silva CL. Interacionismo simbólico: história, pressupostos e relação professor e aluno; suas implicações. Educação por Escrito. 2012;3(2):73-84.

44. Cupertino V, Garcia FC, Honório LC. Prazer e sofrimento na prática docente no ensino superior: estudo de caso em uma IFES mineira. Trab Educ. 2014; 23(3):101-16.

45. Meira TRM, Cardoso JP, Vilela ABA, Amorim CR, Rocha SV, Andrade AN et al. Percepções de professores sobre trabalho docente e repercussões sobre sua saúde. Rev Bras Promoç Saúde. 2014; 27(2):276-82.

46. Soares AGS, Estanilau G, Brietzke E, Lefèvre F, Bressan RA. Percepção de professores de escola pública sobre saúde mental. Rev Saúde Pública. 2014;48(6):940-8.

\section{Endereço para correspondência:}

Christina Cesar Praça Brasil

Universidade de Fortaleza - UNIFOR

Programa de Pós Graduação em Saúde Coletiva

Avenida Washington Soares, 1321

Bairro: Edson Queiroz

CEP: 60.811-905 - Fortaleza - CE - Brasil

E-mail: cpraca@unifor.br 